\title{
Reuna
}

\section{PRINCIPAIS COMPETÊNCIAS EXIGIDAS AOS PROFISSIONAIS DA ÁREA DE CONTROLADORIA EM EMPRESAS COMERCIAIS DA REGIÃO METROPOLITANA DE RECIFE}

\author{
KEY SKILLS REQUIRED TO THE CONTROLLER IN COMMERCIAL COMPANIES OF \\ THE METROPOLITAN REGION OF RECIFE
}

http://dx.doi.org/10.21714/2179-8834/2017v22n2p44-65

\section{Elanuza Gracielly Lira Sá}

Universidade Federal Rural de Pernambuco, DLCH - Campus Dois Irmãos, Brasil

Endereço: Rua Dom Manoel de Medeiros, S/N - Cidade Universitaria - CEP 52171900 - Recife, PE - Brasil Fone: (81) 3320-6460

Email: elanuza gracielly@hotmail.com - Lattes: http://lattes.cnpq.br/0111739722822687

\section{Tânia Nobre Gonçalves Ferreira Amorim}

Universidade Federal Rural de Pernambuco, DLCH - Campus Dois Irmãos, Brasil

Endereço: Rua Dom Manoel de Medeiros, S/N - Cidade Universitaria - CEP 52171900 - Recife, PE - Brasil Fone: (81) 3320-6460

Email: tanobre@gmail.com - Lattes: http://lattes.cnpq.br/2951129655100886

Submissão: 01 Jun. 2017 Publicação: 23 Set. 2017. Sistema de avaliação: Double blind review. Centro Universitário UNA, Belo Horizonte - MG, Brasil. Editor geral: Prof. Dr. Gustavo Quiroga Souki

Apoio e financiamento: CNPq e Universidade Federal Rural de Pernambuco, Dep. de Administração.

Este artigo encontra-se disponível nos seguintes endereços eletrônicos:

http://revistas.una.br/index.php/reuna/article/view/822

http://dx.doi.org/10.21714/2179-8834/2017v22n2p44-65

\section{RESUMO}

A análise das principais competências utilizadas pelos responsáveis do controle organizacional é fundamental para o entendimento do papel da controladoria nas organizações. $O$ presente estudo teve por objetivo analisar as competências individuais utilizadas pelos profissionais de controladoria, em empresas comerciais, da Região Metropolitana do Recife e sua frequência de utilização. A metodologia é exploratória e descritiva e a amostra foi selecionada por conveniência, a partir do uso de questionário junto ao responsável pelos controles internos e gerenciais. Os resultados mostraram que a maioria das empresas não possui uma controladoria totalmente institucionalizada, contudo foi possível identificar as práticas de controles e os profissionais responsáveis. Foi apresentado um rol de competências aos que fazem os controles internos das empresas participantes e a grande maioria delas é utilizada com muita frequência, sendo divididas segundo a classificação proposta por Fleury e Fleury (2004) como: competências técnicas, sociais e de negócios.

Palavras-chave: Competências profissionais; Competências Individuais. Controller, Controladoria; Empresas Comerciais. 


\section{ABSTRACT}

Analysis of the core competencies used by organizational control responsible is critical to understanding the role of controllership in organizations. This study aimed to analyze individual skills used by professionals in controlling trade companies of the Metropolitan Region of Recife and their frequency of use. The methodology is exploratory and descriptive and the sample was selected by convenience from the questionnaire use at the charge of internal and management controls. The results showed that most companies do not have a fully institutionalized controllership, however it was possible to identify the practices of controls and responsible professionals. A list of skills that were presented to make the internal controls of the participating companies and the vast majority is used very often, being divided according to the classification proposed by Fleury and Fleury (2004) techniques, social and business skills.

Keywords: Professional Skills; Individual skills. Controller; Controllership; Commercialcompanies.

\section{Introdução}

Controller é a denominação utilizada por muitas empresas para aquele que atua na controladoria e desenvolve determinadas características e competências técnicas específicas da área. As diretrizes da controladoria apresentam nuances, de acordo com o objetivo de cada organização, frente às mudanças no ambiente organizacional, porque a controladoria tem assumido novas dimensões na gestão de cada empresa, com o passar do tempo (SCHMIDT; SANTOS, 2014).

Assim, o controller, controlador ou responsável pelos controles gerenciais internos desenvolve suas atividades liderando a equipe e gerenciando os resultados almejados pela organização, que nem sempre é exercido por um profissional da área de Ciências Contábeis, como lembrado por Cavalcanti et al. (2012). Deve desenvolver atividades práticas aliadas à gestão, medir as informações, definir os objetivos, planejar, executar e controlar. Contudo, para alcançar a missão e cumprir os objetivos, Crispim, Cabral e Libonati (2011) afirmam que é preciso promover a eficácia organizacional, viabilizar a gestão, articulando e integrando os setores, as pessoas e o ambiente de trabalho. Embora haja uma tentativa de delinear as atividades da Controladoria, elas dependem do modelo de gestão de cada empresa, pois atendem às especificidades e às definições do seu modelo de gestão.

Para Carvalho, Passos e Saraiva (2008), a competência é o eixo entre o relacionamento do indivíduo em propagar um desempenho no qual a qualidade e a capacidade da realização das atividades sejam conforme os padrões estabelecidos, com articulação das informações, conhecimentos e habilidades, no intuito de traduzir as ações e as atitudes no querer ser e agir. Desta forma, as competências estão inerentes às práticas desenvolvidas pelos indivíduos nas organizações. O mérito da gestão talvez esteja em combinar os objetivos organizacionais, por meio de seu processo de planejamento estratégico e das práticas efetivadas na organização. 
A construção de um novo modelo de gestão foi desencadeada, em grande parte, por funções pragmáticas e racionais, que contribuíram para a visão sobre a essência da gestão, despertando nas organizações as competências e o desempenho dos indivíduos. Atingir as expectativas e ser eficiente não dependia apenas das ações, mas de como planejar e agir. Desta forma, mobilizar os recursos, as habilidades, os conhecimentos e as aptidões geram valor econômico para as organizações e social para os indivíduos envolvidos (FLEURY e FLEURY, 2002).

As competências técnicas fundamentais para a função de controller podem ser apresentadas no intuito de projetar, de gerar e de consolidar informações voltadas para o planejamento e controle da organização. Assim, esta pesquisa busca responder à seguinte questão: quais são as principais competências individuais utilizadas pelos profissionais de controladoria em empresas de comércio da Região Metropolitana do Recife? Portanto, o objetivo deste estudo é analisar as competências individuais dos controllers e sua frequência de utilização nas organizações pesquisadas.

A presente pesquisa se justifica por contribuir para a identificação das competências individuais dos controller nas empresas comerciais pesquisadas. A análise das principais competências exigidas aos profissionais da área de controladoria é fundamental para identificar o perfil dos responsáveis pelos controles internos gerais, além de identificar as competências técnicas, sociais e de negócios caracterizadas como essenciais para atuação e desenvolvimento das atividades de controladoria nas empresas.

\section{Revisão da Literatura}

\subsection{A Controladoria}

O estudo da controladoria pode ser abordado sob dois aspectos: como unidade administrativa e como campo de conhecimento. Como uma unidade administrativa ou um órgão possui missão, funções e princípios, baseados no modelo de gestão da empresa. A missão da controladoria pode ser vista como cuidar da organização, como um todo, para eficácia de seus resultados. Já como área de conhecimento humano envolve conceitos, fundamentos e métodos provenientes de outras ciências e que se constituem em bases teóricas relativas ao controle do processo de gestão organizacional. (CATELLI, 2001; BORINELLI, 2006; MORANTE; JORGE, 2008; MONTEIRO; BARBOSA, 2011).

O conjunto de conhecimentos reunidos pela controladoria se relaciona com a empresa e com o próprio ambiente empresarial, ou seja, integra conhecimentos diversos com o ambiente empresarial. Por outro lado, pensar na controladoria como órgão ou unidade é primordial para o desempenho de suas funções e alcance dos objetivos. Nesta perspectiva, Padoveze (2005) e Cuganesan, Dunford e Palmer (2012) afirmam que a controladoria se volta para o desempenho da empresa por integrar os procedimentos entre os departamentos, coordenados pelo seu gestor, que é denominado Controller, controlador interno ou contador gerencial.

A controladoria, segundo Lunkes e Schnorrenberger (2009), era inicialmente fortemente ligada ao controle financeiro. No entanto, usar controle e controladoria 
como sinônimos é algo impensável, porque a controladoria evoluiu para uma abrangência maior e mais estratégica. Ela ajuda os gestores na tomada de decisão, pois gera informações, que servem de suporte para a eficácia do processo de gestão e decisão organizacional.

A controladoria então pode ser vista como uma área, divisão ou setor responsável por uma função organizacional sobre o qual o gestor tem autoridade para desempenhar atividades específicas (MAXIMIANO, 2006; OLIVEIRA, 2004). Desta forma, Borinelli (2006) salienta que a controladoria deve ser embasada por fontes teóricas que atribuem conhecimentos aos responsáveis pelos controles na área operacional, econômica, financeira e patrimonial das empresas, de modo que as informações sejam avaliadas em termos do resultado organizacional.

A organização não é um sistema isolado, ela se relaciona com entidades e variáveis que podem afetar seu desempenho e sobre as quais não tem controle (FARIA, 2007). Para Dias (2002, p.56), a controladoria pode ser entendida como um: "sistema aberto e dinâmico que interage constantemente com 0 ambiente organizacional", já que é efetivamente influenciada pelo ambiente interno e externo.

A finalidade da controladoria é garantir informações adequadas ao processo decisório, de forma que colabore com os gestores na busca pela eficácia gerencial. (FIGUEIREDO; CAGGIANO, 2004). Segundo Lunkese Schnorrenberger (2013), no Brasil $100 \%$ dos pesquisadores julgam o planejamento como a função mais relevante da controladoria, já nos EUA e na Alemanha, esta opinião é de $80 \%$. Nem todas as empresas possuem o órgão controladoria, mas a ausência de controller será suprida por um gestor ou diretor, que possua uma visão geral da organização.

Os estudos sobre controladoria como unidade administrativa, ou seja, como parte da estrutura organizacional da empresa, concentram-se em pesquisas sobre as funções da controladoria, seu papel na empresa e sua institucionalização. Segundo Borinelli (2006), autores brasileiros, no entanto, iniciaram pesquisas sobre a controladoria como área do saber ou ramo de conhecimento, com conceitos, finalidade e objeto de estudo próprios.

Em empresas que apresentam uma estrutura linear, os gestores da controladoria exercem as atividades atribuídas ao controle e a tomada de decisão, enquanto uma estrutura com órgãos de staff utiliza um aconselhamento e assessoria especializada devidamente estruturada. Para alguns autores, o ideal seria a controladoria como órgão de linha-staff, ou seja, a junção das atividades fins com as atividades meio, assessoramento e voz de comando, ou ainda, uma junção da hierarquia com a consultoria (CHAGAS; BONZAMINI, 2003; BORINELLI, 2006).

Borinelli (2006) afirma que autores nacionais ao estudarem a controladoria enfatizam que a mesma deve realizar planejamento, coordenar planos, fazer parte do processo decisório, e outras atividades, considerando-a como órgão de linha. Já para autores estrangeiros, a controladoria se limita ao assessoramento e suporte, o que a caracteriza como órgão de staff. Em outras palavras, Chagas e Bonzamini (2003) afirmam que o pessoal de linha tem autoridade sobre a gestão e decisões da unidade, mas os órgãos de staff são um assessoramento técnico e especializado que irá apoiar a gestão organizacional, através dos órgãos de linha. 
Por fim, a partir do que foi estudado se entende a controladoria como um órgão ou área importante para qualquer organização, que decide e executa atividades diversas voltadas ao apoio de decisões táticas e estratégicas, no âmbito gerencial, fiscal e tributário. Assim, como afirmam Diehl e Rodniski (2012), dependendo da estrutura hierárquica da organização, a controladoria poderá ser vista como parte da contabilidade ou autônoma, uma unidade organizacional de linha ou de staff, ou até mesmo ser desenvolvida por um profissional em termos de consultoria, porque possui caráter consultivo e de apoio à cúpula organizacional.

\subsection{Competências}

O termo "competência" tem origem do latim pela palavra competentia, que significa "a qualidade de quem é capaz de apreciar e resolver certo assunto, de fazer determinada coisa, com capacidade, habilidade, aptidão e idoneidade" (CARDOSO; MENDONÇA NETO; OYADOMARI, 2010, p. 93).

Para Sandberg (2000) e Sandberge Dall'Alba (2006), os estudos em competência podem ser agrupados em torno de duas perspectivas, as racionalistas ou funcionais e as interpretativas. As investigações iniciais sobre competência tendiam a enfatizar a sua relação com o desempenho individual. Nesta visão, o conceito de competência, no contexto organizacional, começou a ser desenvolvido sob a perspectiva do indivíduo, talvez sob a influência de autores americanos como McClelland (1973), que define competências como habilidade, conhecimento e aptidão, ou seja, características implícitas a uma pessoa, que realiza as tarefas com grande desempenho. Competência demonstra que o talento da pessoa com a sua prática gera habilidades e a concepção ao realizar as tarefas, gera o conhecimento. McClelland talvez tenha sido um dos primeiros autores a identificar atitudes e hábitos que enfatizam as primeiras características para o modelo de competências, com base nas necessidades da organização. Nos anos de 1980, o interesse nos estudos em competência passou a enfatizar o trabalho gerencial, por autores como Boyatzis (1982) e Spencer e Spencer (1993).

Segundo Prahalad e Hamel (1990), as competências são apresentadas como dimensões no contexto organizacional, sugerindo subdivisões em três dimensões: essenciais, funcionais $e$ individuais. As Competências Essenciais são as competências pontuais atribuídas à razão da sobrevivência da organização e se apresentam como diferencial perante concorrentes e clientes. Competências Funcionais são as competências específicas distribuídas nas áreas vitais das organizações, e Competências Individuais são as competências inerentes ao indivíduo, que são compreendidas e estendidas às competências gerencias.

O conjunto de conhecimentos, de habilidades e de aptidões faz parte da essência da atividade do indivíduo. Tais competências estão diretamente relacionadas com o desempenho, o qual pode ser mensurado por características preestabelecidas, para posteriormente ser melhorado e desenvolvido por treinamentos e desenvolvimentos (PARRY, 1996).

As abordagens interpretativas do estudo das competências, diferentemente, defendem que a competência é dependente do contexto "[...] constituída pelo significado que o trabalho toma para o trabalhador em sua experienciação do 
mesmo" (SANDBERG, 2000, p. 11). "A competência é a faculdade de mobilizar redes de atores em torno das mesmas situações, é a faculdade de fazer com que esses atores compartilhem as implicações de suas ações, é fazê-los assumir áreas de corresponsabilidade" (ZARIFIAN, 2001, p. 74). Le Boterf (2003) aborda a questão de complexidade do trabalho, considerando que a competência do indivíduo é saber administrar essa complexidade, com adequada mobilização de recursos pessoais e do meio em que está inserida. E a interação social leva a buscar as competências que faltam ao profissional, através de sua rede social, permitindo 0 compartilhamento dos resultados da ação.

Assim, a capacidade de coordenar e gerenciar recursos cria as competências e capacidades organizacionais (BORINI; FLORIAI; FLEURY, 2012). A competência tem como objetivo apoiar o estabelecimento das estratégias das organizações, em seus processos internos, passando a adequar as atividades que eram apenas operacionais, regidas por ações mecânicas para a construção de ações regidas por competência, apresentadas por aptidões, habilidades e conhecimentos, segundo Reis et al.(2015). Para Resende (2003), as aptidões, habilidades e conhecimentos são transformações da competência por reunir todos os conhecimentos inerentes à formação, ao treinamento, às experiências e ao autodesenvolvimento, além das habilidades, interesse e vontade, apresentadas pelo comportamento do indivíduo em redes sociais.

Fleury e Fleury (2004) classificam as competências individuais em três categorias: Competências de Negócios, que são relacionadas à interação da empresa com oportunidades, ameaças, pontos fortes e fracos do negócio; as Competências Técnico-Profissionais que são os inputs do conhecimento ou experiência técnica do trabalhador, com relação a sua área de atuação; e as Competências Sociais, que enfatizam a interação com as pessoas nas organizações. Esta classificação foi a utilizada neste trabalho.

Sob a perspectiva profissional, que define a relação do funcionário com o trabalho, a construção do conceito da competência é enfatizada por Fleury e Fleury (2000; 2004) por não se limitar aos conhecimentos, habilidades ou técnicas, mas se apoiando nos saberes, saber fazer e saber ser. A competência não é um estado nem um conhecimento que se possui, ela é contingencial, inserida no contexto de atualização e de flexibilização da capacidade de cada indivíduo ou grupo de pessoas, ou seja, a competência é um saber agir, mobilizar, transferir, aprender e se engajar, tendo uma visão estratégica para assumir responsabilidade, agregando valor econômico para as organizações e valor social para os indivíduos.

Aprimorando o conceito de competência, Dutra, Fleury e Ruas (2008) afirmam ser construída através da correlação entre o conhecimento e as atitudes inerentes ao papel e a responsabilidade da pessoa no trabalho, com o desenvolvimento de performance, como uma habilidade das pessoas que pode ser adquirida para associar o conceito às suas realizações e aquilo que elas proveem, produzem ou entregam.

Nas organizações, as ações adotadas e os padrões das competências dos indivíduos são diferenciais estratégicos. A incorporação de tecnologias e práticas gerenciais gera valor ao indivíduo como diferencial competitivo, porque as pessoas 
responsáveis por gerenciar apresentam tendências em reagir positivamente a mudanças, e a busca do diferencial competitivo estabelece a capacidade e condicionantes para reformulações nas organizações (AMORIM; SILVA, 2011).

Dessa forma, Ba, Castro e Souza (2013) destacam a importância das competências individuais considerando as pessoas, dentre os demais recursos, o mais utilizado pelas organizações, porque as competências são essenciais no processo de gestão de pessoas.

\subsection{As competências do Controller}

O responsável pela controladoria é chamado de controller em muitas empresas. Lunkes e Schnorrenberger (2009) afirmam que o termo tem origem do latim, que denominava um segundo registro ou um registro paralelo para fins de controle da movimentação de recursos da organização. O termo também tem como referência a palavra contrerôle do francês e counterroller do inglês, que significam aquele que controla a entrada e saída de dinheiro e mercadorias.

$\mathrm{Na}$ Inglaterra, o comptroller se referia a cargos do controle de contas e o surgimento dos primeiros contollers foi no setor estatal. Já nos Estados Unidos, em busca de maior transparência, foi criado o cargo de comptroller por volta dos anos de 1778 , mais uma vez no setor público. Já no setor privado, a controladoria apareceu na segunda metade do Século XIX nas empresas americanas (LUNKES; SCHNORRENBERGER, 2013).

Ser gestor é desenvolver no indivíduo as características de competências técnicas e cognitivas de comandar pessoas e unidades organizacionais. Fagundes e Seminotti (2009) afirmam que a palavra gestor é utilizada para sinalizar a coexistência, tanto dos aspectos de liderança, quanto dos aspectos gerenciais em um profissional que responde por uma unidade organizacional. No início, o controller geralmente não ocupava cargos gerenciais e atuava mais no nível operacional. Atualmente, este profissional, muitas vezes, ocupa cargo gerencial e atua em nível estratégico em diversas organizações.

O controller pode ser o gerente encarregado da contabilidade, que fornece informações importantes como suporte ao planejamento e controle, familiarizado com as demais áreas da empresa (GARRISON; NOREEN; BREWER, 2001; FIGUEIREDO; CAGGIANO, 2004). Já para Crispim, Cabral e Libonati (2011), a controladoria auxilia a coordenar o comportamento organizacional, utilizando sistemas de controle gerenciais, que influenciam o comportamento das pessoas, buscando alinhar seus objetivos aos da empresa.

Importante salientar que as funções do controller variam de organização para organização, no entanto, de forma geral, o seu papel está ligado ao auxílio da gestão na tomada de decisão, ou seja, prover informações que irão estimular a organização a alcançar seus objetivos, além de desenvolver informações sobre o impacto financeiro das ações da organização. Portanto, o controller desempenha múltiplos papéis, que exigem uma vasta gama de competências (CALIJURI; SANTOS; SANTOS, 2005; COLTON, 2001; EMSLEY, 2005). 
Segundo Lunkeset al. (2011), as funções do controller são fundamentadas na contabilidade. Com o tempo, este profissional passou a assumir novas competências como: funções de suporte informacional, controle interno, planejamento tributário, elaboração do orçamento, medidas operacionais, formulação de estratégias, gestão da informação, planejamento estratégico das organizações, dentre outras.

Gerenciar a controladoria é proporcionar uma gestão, que se expande por todas as áreas da empresa, com uma visão sistemática. Competências como gerar relatórios para auxiliar a tomada de decisões, medir os riscos e monitorar os resultados em busca da eficiência são inerentes ao controller. O domínio sobre conhecimentos financeiros, contábeis e administrativos são princípios fundamentais, atrelados aos valores morais e éticos para um trabalho eficaz (FAGUNDES; SEMINOTTI, 2009; BRAGG, 2009; CRISPIM; CABRAL; LIBONATI, 2011).

Küpper (2005) defende que o controller precisa das seguintes competências: conhecimento das áreas a serem coordenadas e suas inter-relações, conhecimento teórico e prático amplo e atualizado. Conhecimento das teorias econômicas e visão econômica na função de assessoria aos outros gestores. Conhecimento de teorias comportamentais, instrumentos e técnicas de motivação e criatividade. Autores como Anthony; Govindarajan (2002), Horngren, SundemeStratton (2004) defendem as competências de um controller como: elaboração de orçamentos; controle interno; relatórios contábeis; auditoria interna; avaliação de desempenho econômico; sistemas de contabilidade; controle de seguros; relatórios do governo e gestão fiscal.

Conforme apresentado, o controller é um profissional, que deve possuir uma vasta gama de competências que o leva a ter conhecimentos não apenas na área contábil e de custos, mas que também englobem uma visão de análise externa da organização, influências e expectativas futuras de crescimento e desenvolvimento.

\section{Metodologia}

Para atingir o objetivo proposto para esta pesquisa foram adotados procedimentos metodológicos apropriados. Metodologia de pesquisa é definida por Minayo (2003) como sendo o caminho do pensamento a ser seguido. Ocupa um lugar central na teoria e é, basicamente, o conjunto de técnicas a serem adotadas para construir uma realidade.

Quanto aos objetivos, esta pesquisa se caracteriza como exploratória e descritiva. De acordo com Raupp e Beuren (2006), pesquisas exploratórias possibilitam uma visão geral do fato e são utilizadas, quando o tema escolhido é pouco explorado e sobre ele é difícil formular hipóteses precisas e operacionalizáveis, bem como proporcionam o aprofundamento de conhecimentos. Já Gil (2008) e Creswell (2010) destacam que as pesquisas descritivas buscam descrever as características de determinada população ou fenômeno.

Como instrumento de coleta de dados foi utilizado o questionário, elaborado exclusivamente para a pesquisa, a partir do levantamento bibliográfico realizado. $O$ questionário foi dividido em cinco partes: Perfil organizacional da empresa; Perfil do profissional responsável pela controladoria; Competências Técnicas, Competências Sociais e Competências de Negócios, as quais foram apresentadas aos participantes através de uma Escala Likert com quatro níveis (não usa; usa pouco; 
geralmente usa e usa muito) para que os respondentes identificassem o nível e utilização de cada competência.

Com o objetivo de identificar o perfil dos responsáveis pelos controles internos gerais das empresas pesquisadas, além de identificar as competências técnicas, sociais e de negócios caracterizadas como essenciais, para atuação e desenvolvimento das atividades de controladoria nas empresas, foi adotado para o desenvolvimento da pesquisa, as três categorias classificadas por Fleury e Fleury (2004), conforme apresentado anteriormente.

A população de uma pesquisa se refere aos sujeitos, que se constituem objeto de estudo. Foi constituída pelos profissionais, que desenvolvem atividades da área de controladoria e controles internos gerais, nas empresas comerciais da Região Metropolitana de Recife, Pernambuco. Composta inicialmente por uma amostra de 10 empresas comerciais de pequeno e médio porte, a pesquisa foi ampliada para 20 empresas, seguindo o mesmo perfil. Vale destacar que a amostra foi selecionada por conveniência, o que representa uma limitação do estudo, a partir das redes de relacionamento das autoras.

\section{Apresentação e análise dos resultados}

\subsection{Perfil das empresas pesquisadas}

O campo organizacional pode ser definido por uma estrutura dinâmica, que apresenta em seu interior, as práticas no processo organizacional, bem como as ações dos responsáveis pelas funções da empresa, que habilitam 0 desenvolvimento (MAXIMIANO, 2006). Desta forma, busca-se inicialmente analisar o perfil organizacional para melhor entender os aspectos dos indivíduos responsáveis pela controladoria e da organização como o todo.

Destaca-se que a maioria das empresas que participou da pesquisa é de pequeno e médio porte, seguindo a definição do Serviço Brasileiro de Apoio a Micro e Pequena Empresa - SEBRAE, em que as microempresas comerciais têm até 19 empregados; as Pequenas: de 20 a 99 empregados; as Médias: de 100 a 499 empregados e as Grandes: mais de 500 empregados. No estudo realizado foi identificado que quanto maior o número de funcionários, maior a presença das atividades de controladoria nas empresas.

Apesar de a amostra estudada ter sido ampliada, não foram identificadas alterações significativas em termos do perfil de empresa analisado. Observa-se que a controladoria não é um departamento instituído na maioria das organizações pesquisadas, provavelmente, em virtude do porte. Entretanto, foi identificado que no grupo de empresas de médio porte, grande parte possui uma unidade de controladoria, ou mesmo identifica claramente que o contador ou o sócio desempenha esse papel. Isto só ocorreu com uma pequena quantidade de empresas de pequeno porte.

Isso reflete um resultado que, até certo ponto, já era esperado, uma vez que segundo o levantamento bibliográfico desenvolvido, em outros estudos realizados junto a micro e pequenas empresas no Brasil, a maioria não possui um setor de 
controladoria instalado ou identifica as atividades da área, como exemplo, os de Queiroz (2005), Fernandes (2007) e Cunha Junior (2009), contudo, muitas identificam que as práticas de controle são realizadas pelos diretores, sócios ou gerentes. Corrobora também com Diehl e Rodniski (2012), quando afirmam que dependendo da estrutura hierárquica da organização, a controladoria poderá ser vista como parte da contabilidade, autônoma, ou até mesmo ser desenvolvida por um profissional de apoio à cúpula organizacional.

Concorda-se com Fernandes e Galvão (2016, p.16), quando defendem que "embora haja muita resistência por parte das MPE's quanto à adoção da controladoria como ferramenta de gestão, é possível defender sua viabilidade, uma vez que se pode adequá-la à estrutura organizacional, independente do porte da empresa". Já Queiroz (2005) identificou, que o uso das informações contábeis, por micro e pequenos empresários envolve, basicamente, aspectos econômico-financeiros. Isto também foi identificado neste estudo, pois a maioria das empresas pesquisadas demonstrou que apenas realiza análises financeiras, contábil e fiscal-tributária. A síntese do perfil das empresas pesquisadas é apresentada no quadro 2.

Quadro 2 - Perfil Organizacional

\begin{tabular}{|c|l|c|}
\hline \multicolumn{1}{|c|}{ Variável } & \multicolumn{1}{|c|}{ Níveis da variável } & $\%$ \\
\hline \multirow{2}{*}{ Porte da Empresa } & Pequena & $30 \%$ \\
\cline { 2 - 3 } & Média & $70 \%$ \\
\hline \multirow{3}{*}{ No de Funcionários } & Até 50 & $50 \%$ \\
\cline { 2 - 3 } & De 51 a 100 & $20 \%$ \\
\cline { 2 - 3 } & De 101 a 499 & $30 \%$ \\
\cline { 2 - 3 } & A partir de 500 & - \\
\hline \multirow{2}{*}{ Possui Controladoria } & Sim & $70 \%$ \\
\cline { 2 - 3 } & Não & $30 \%$ \\
\hline \multirow{3}{*}{ Denominação do Responsável } & Sócio - Administrativo & $30 \%$ \\
\cline { 2 - 3 } & Diretoria & $30 \%$ \\
\cline { 2 - 3 } & Gerência & \\
\hline
\end{tabular}

Fonte: elaborado pelas autoras com base nos dados da pesquisa

\subsection{Análise do perfil dos responsáveis pelos controles gerais}

Como destacado na seção anterior, embora a maioria das empresas não tenha a controladoria como uma unidade administrativa, as práticas de controle existem em grande parte e há um responsável por elas. Estudos como os de Cunha Jr (2009) mostraram que o processo de controle e de gestão adotados nas micro e pequenas empresas será determinante significativo de sucesso ou fracasso. Em algumas empresas pesquisadas, o responsável pela controladoria ou controles internos, expressou a importância dos controles para o sucesso organizacional.

Quanto ao gênero dos profissionais, que desenvolvem as atividades de controladoria, nas empresas pesquisadas, não se identificou qualquer preponderância. Este dado foi curioso, uma vez que estudos como os de Crispin, Cabral e Libonati (2011) identificaram predominância masculina dentre os controllers. No entanto, como neste estudo, na maioria das empresas não existe um órgão de controladoria estabelecido, talvez tenha sido por isto que não houve predominância masculina. 
Quanto à faixa etária dos responsáveis pelos controles gerais nas empresas pesquisadas, a maioria tem acima de 40 anos, sendo formado por profissionais que já estão no mercado há alguns anos e, provavelmente, estabilizados na carreira. Wahlmann (2003), ao estudar microempresas em São Paulo, identificou que os empresários possuem boa experiência profissional e, principalmente, nas áreas de Administração e Economia, o que de certo modo foi confirmado neste estudo, porque todos os profissionais responsáveis pelo controle possuem formação superior, destacando-se os cursos de Administração e Ciências Contábeis, o que representa um dado bastante significativo na amostra trabalhada, por ser formada por pequenas e médias empresas. Monteiro e Barbosa (2011) salientam a interdisciplinaridade das atividades da controladoria, o que corrobora com a formação dos responsáveis nas empresas pesquisadas.

Todos os pesquisados terem nível superior foi surpreendente, porque segundo a Pesquisa Nacional de Domicílios (PNAD, 2014), três em cada dez pessoas da força de trabalho brasileira não têm sequer o Ensino Fundamental. Apenas $16 \%$ dos trabalhadores brasileiros têm Ensino Superior completo e a pior situação região Nordeste.

Entretanto, menos da metade dos respondentes da pesquisa possui formação em pós-graduação. Dentre os que já fizeram uma pós-graduação, os cursos de Gestão Financeira e Controladoria, Finanças Corporativas e Gestão de Negócios foram os mais citados. Isto talvez sugira uma maior necessidade de aprimoramento dos estudos por parte dos pesquisados, uma vez que em 2016 há na Região Metropolitana do Recife doze cursos de pós-graduação lato sensu na área de controladoria e finanças, segundo levantamento realizado pelas autoras.

O conhecimento em língua estrangeira é representado pelo inglês e espanhol, dentre os pesquisados. Na amostra trabalhada, a maioria afirmou ter o inglês em nível básico e $20 \%$ não possui qualquer conhecimento em idiomas. Apenas uma pequena parcela possui conhecimentos básicos da língua espanhola. Segundo os respondentes não há grande necessidade de terem fluência em outro idioma, pois possuem atuação local. Isto vem a confirmar o que Machado et al. identificaram em seus estudos, pouca importância dada ao conhecimento em outros idiomas pelos controllers das 100 maiores empresas de Santa Catariana.

O quadro 3 a seguir apresenta uma síntese do perfil dos profissionais responsáveis pelas atividades de controladoria nas empresas pesquisadas. 
Quadro 3 - Perfil dos Controles Gerais

\begin{tabular}{|clc|}
\hline VARIÁVEL & \multicolumn{1}{c}{ NíVEIS DA VARIÁVEL } & $\%$ \\
\hline \multirow{2}{*}{ Gênero } & Masculino & $50 \%$ \\
\cline { 2 - 3 } & Feminino & $50 \%$ \\
\hline \multirow{3}{*}{ Faixa Etária } & Até 30 anos & $10 \%$ \\
\cline { 2 - 3 } & De 31 a 40 & $30 \%$ \\
\cline { 2 - 3 } & De 41 a 50 & $40 \%$ \\
\cline { 2 - 3 } Formação Superior & Sais 50 & $20 \%$ \\
\hline \multirow{2}{*}{ Formação - Pós-Graduação } & Não & $100 \%$ \\
\hline \multirow{3}{*}{ Tempo de Experiência } & Sim & $0 \%$ \\
\cline { 2 - 3 } & Não & $40 \%$ \\
\hline & Até 5 ANOS & $60 \%$ \\
\cline { 2 - 3 } & De 6 A 10 Anos & $10 \%$ \\
\cline { 2 - 3 } & De 11 A 15 Anos & $40 \%$ \\
\cline { 2 - 3 } & De 16 A 20 Anos & $30 \%$ \\
\hline \multirow{2}{*}{ Idiomas } & Inglês & $70 \%$ \\
\cline { 2 - 3 } & Espanhol & $10 \%$ \\
\cline { 2 - 3 } & Não Possui & $20 \%$ \\
\hline
\end{tabular}

Fonte: elaborado pelas autoras com base nos dados da pesquisa

\subsection{Análise das competências técnicas}

O foco do trabalho esteve no estudo das competências individuais dos controllers ou profissionais, que atuam na controladoria e sua frequência de utilização nas organizações pesquisadas. Quando analisadas as competências técnicas dos responsáveis pelos controles gerais, percebeu-se um amplo conhecimento declarado em termos das atividades de controladoria, mesmo quando uma unidade organizacional ainda não esteja formalizada na organização. Isto vem confirmar outros estudos, quando identificam que mesmo não possuindo uma unidade de controladoria, muitas empresas de pequeno e médio porte realizam seus controles internos, como os de Fernandes e Galvão (2016).

Foram apresentadas dezenove competências técnicas aos participantes da pesquisa, extraídas do levantamento bibliográfico realizado, para que eles respondessem a frequência de utilização das mesmas. Destas, apenas três foram identificadas por uma pequena parte da amostra como nunca sendo utilizadas: Conhecimentos na área comercial/produção supervisiona o funcionamento de todos os setores da empresa e elabora o Orçamento Anual (Budget). De certo modo, estas repostas já eram esperadas, porque como grande parte das empresas era de pequeno porte, estes não possuíam uma unidade administrativa de controladoria, então o sócio é que realiza as atividades de controle.

Metade dos participantes respondeu que usa pouco a competência Conhecimentos na área de Recursos Humanos, o que pode ser entendido como preocupante, porque para qualquer gestor é necessário entender sobre as pessoas e sua gestão, em especial, quanto toda a amostra trabalhada ocupa uma função gerencial na sua empresa, conforme afirmam Amorim e Silva (2011). 
Em contraponto, todos os participantes afirmaram que usam muito as competências: fornece suporte informacional à gestão empresarial e elabora relatórios gerenciais. Comprovando grande importância dessas competências para o trabalho de controle interno também defendido por autores como Kupper (2005), Anthony; Govindarajan (2002), Horngren, SundemeStratton (2004), que salientam dentre as competências de um controller a elaboração de orçamentos; controle interno; relatórios contábeis e suporte à gestão.

A maciça maioria dos participantes também respondeu que usa muito as competências: Assessora a cúpula administrativa, Conhecimentos na área financeira e Supervisiona a contabilidade. Estas respostas eram esperadas, pois segundo o levantamento bibliográfico, estas competências estão dentre as mais citadas para a área. Todas as demais competências técnicas apresentadas aos participantes foram respondidas como muito utilizadas, por grande parte deles. Observando assim, que os responsáveis pelos controles internos pesquisados atuam como forte apoio frente aos conhecimentos necessários para o planejamento, controle e gerenciamento da organização, o que vem a confirmar outros achados como os dos autores Calijuri, Santos e Santos (2005), Colton (2001), Lunkes e Schnorrenberger (2009) e Diehl e Rodniski (2012). O quadro 4 apresenta a síntese desses resultados:

Quadro 4 - Percentual de Utilização das Competências Técnicas

\begin{tabular}{|c|c|c|c|c|}
\hline \multirow{2}{*}{$\begin{array}{c}\text { Competências técnicas do responsável pelos } \\
\text { controles gerais (controller) }\end{array}$} & \multicolumn{4}{|c|}{ Frequência de uso } \\
\hline & $\begin{array}{l}\text { Não } \\
\text { usa }\end{array}$ & $\begin{array}{l}\text { Usa } \\
\text { pouco }\end{array}$ & $\begin{array}{l}\text { Geralmente } \\
\text { usa }\end{array}$ & $\begin{array}{l}\text { Usa } \\
\text { muito }\end{array}$ \\
\hline Conhecimentos na área financeira & - & - & $20 \%$ & $80 \%$ \\
\hline Conhecimentos na área contábil & - & - & $30 \%$ & $70 \%$ \\
\hline Conhecimentos na área fiscal/tributária & - & - & $30 \%$ & $70 \%$ \\
\hline Conhecimentos na área de tecnologia da informação (TI) & - & $10 \%$ & $80 \%$ & $10 \%$ \\
\hline Conhecimentos na área de Recursos Humanos & - & $50 \%$ & $20 \%$ & $30 \%$ \\
\hline Conhecimentos na área comercial/produção & $10 \%$ & $20 \%$ & $20 \%$ & $50 \%$ \\
\hline Elabora diretrizes de controles internos & & $20 \%$ & $10 \%$ & $70 \%$ \\
\hline Elabora o Orçamento Anual (Budget) & $30 \%$ & $10 \%$ & $20 \%$ & $40 \%$ \\
\hline Gerencia indicadores de desempenho & - & - & $50 \%$ & $50 \%$ \\
\hline Supervisiona as atividades nas áreas de custos & - & $10 \%$ & $20 \%$ & $70 \%$ \\
\hline Fornece os dados contábeis oportunos e precisos & - & $10 \%$ & $30 \%$ & $60 \%$ \\
\hline $\begin{array}{l}\text { Supervisiona o funcionamento de todos os setores da } \\
\text { empresa }\end{array}$ & $10 \%$ & $10 \%$ & $20 \%$ & $60 \%$ \\
\hline Supervisiona a contabilidade & - & - & $20 \%$ & $80 \%$ \\
\hline Fornece suporte informacional à gestão empresarial & - & - & - & $100 \%$ \\
\hline Elabora relatórios gerenciais & - & - & - & $100 \%$ \\
\hline Assessora a cúpula administrativa & - & - & $10 \%$ & $90 \%$ \\
\hline Realiza análise de custos & - & - & $40 \%$ & $60 \%$ \\
\hline Realiza análise de índices contábeis & & - & $50 \%$ & $50 \%$ \\
\hline Elabora o Planejamento Financeiro Organizacional & $10 \%$ & $10 \%$ & $20 \%$ & $60 \%$ \\
\hline $\begin{array}{l}\text { Age como consultor interno em todas as áreas da } \\
\text { empresa }\end{array}$ & 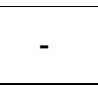 & $10 \%$ & $30 \%$ & $60 \%$ \\
\hline
\end{tabular}

Fonte: elaborado pelas autoras com base nos dados da pesquisa 


\subsection{Análise das competências sociais}

As competências sociais estão relacionadas com a interação entre as pessoas nas organizações, seja em processos de negociação, trabalho em equipe, expressar ideias, motivar, dentre outras atividades, segundo Fleury e Fleury (2004). Foram apresentadas vinte e uma competências sociais aos participantes, extraídas do levantamento bibliográfico realizado para o estudo.

Todos responderam que usam muito apenas uma das competências listadas: é persistente e não desiste frente aos obstáculos. Isto representa o esforço dos responsáveis pelas atividades de controladoria no sentido de não desistir e buscar os melhores resultados. Está diretamente associada às competências: ter postura proativa e realizadora, ter integridade e confiança e gerencia conflitos no ambiente de trabalho, que também obtiveram percentuais de muito uso bem elevados. Estas competências também foram identificadas nos estudos de Machado et al. (2010) como muito importantes para os controllers de Santa Catarina.

É interessante salientar que nenhuma competência social foi listada como não sendo utilizada pelos participantes da pesquisa, o que sugere que as competências sociais apresentadas aos responsáveis pelos controles gerenciais internos das empresas pesquisadas estão, efetivamente, sendo utilizadas por todos eles, confirmando o que foi identificado no levantamento bibliográfico realizado. No entanto, algumas competências foram listadas por uma minoria como pouco utilizadas, mas a maior parte dos gestores participantes respondeu que, geralmente, usam ou usam muito.

As competências listadas como muito utilizadas por $70 \%$ ou mais dos respondentes estão diretamente relacionadas a uma postura gerencial, de liderança e de desenvolvimento profissional, que são substanciais para bons gestores: comunicase, oralmente, com clareza e objetividade; tem integridade e confiança; escreve com clareza e objetividade; sabe negociar com pessoas; tem capacidade de prever problemas interpessoais; tem postura proativa e realizadora; busca 0 autodesenvolvimento; tem capacidade de autocrítica e tem controle emocional; gerencia conflitos no ambiente de trabalho. Isto vem a confirmar os estudos que defendem $o$ aspecto gerencial, que a área de controladoria tem assumido nos últimos anos, deixando de ser apenas operacional para ser um apoio à gestão organizacional efetiva, como os de Chagas e Bonzamini (2003), Borinelli (2006), Lunkes e Schnorrenberger (2013) e Schmidt e Santos (2014), dentre outros citados anteriormente. A seguir, o quadro 5 sintetiza as competências sociais e sua utilização. 
Quadro 5 - Percentual de Utilização das Competências Sociais

\begin{tabular}{|c|c|c|c|c|}
\hline \multirow{2}{*}{$\begin{array}{l}\text { Competências Sociaisdo responsável pelos } \\
\text { controles gerais (controller) }\end{array}$} & \multicolumn{4}{|c|}{ Frequência de uso } \\
\hline & $\begin{array}{l}\text { Não } \\
\text { usa }\end{array}$ & $\begin{array}{l}\text { Usa } \\
\text { pouco }\end{array}$ & $\begin{array}{c}\text { Geralmente } \\
\text { usa }\end{array}$ & $\begin{array}{c}\text { Usa } \\
\text { muito }\end{array}$ \\
\hline Interage bem com as pessoas & - & $10 \%$ & $30 \%$ & $60 \%$ \\
\hline Possui liderança e sabe gerir pessoas & - & - & $40 \%$ & $60 \%$ \\
\hline Tem flexibilidade nas relações interpessoais & - & $10 \%$ & $70 \%$ & $20 \%$ \\
\hline Sabe formar equipes cooperativas e comprometidas & - & - & $70 \%$ & $30 \%$ \\
\hline Estimula o aprendizado da equipe & - & - & $50 \%$ & $50 \%$ \\
\hline Estimula o desenvolvimento profissional da equipe & - & - & $40 \%$ & $60 \%$ \\
\hline Tem integridade e confiança & - & - & $10 \%$ & $90 \%$ \\
\hline Sabe trabalhar em equipe & - & - & $50 \%$ & $50 \%$ \\
\hline Comunica-se, oralmente, com clareza e objetividade & - & - & $30 \%$ & $70 \%$ \\
\hline Escreve com clareza e objetividade & - & - & $30 \%$ & $70 \%$ \\
\hline Sabe negociar com pessoas & - & $10 \%$ & $20 \%$ & $70 \%$ \\
\hline Tem capacidade de prever problemas interpessoais & - & $10 \%$ & $20 \%$ & $70 \%$ \\
\hline Tem capacidade de solucionar problemas interpessoais & - & $10 \%$ & $30 \%$ & $60 \%$ \\
\hline É persistente e não desiste frente aos obstáculos & - & - & - & $100 \%$ \\
\hline Tem postura proativa e realizadora & - & - & $20 \%$ & $80 \%$ \\
\hline Busca o autodesenvolvimento & - & $10 \%$ & $20 \%$ & $70 \%$ \\
\hline Tem capacidade de autocrítica & - & $20 \%$ & $10 \%$ & $70 \%$ \\
\hline Sabe ouvir os outros & - & $10 \%$ & $30 \%$ & $60 \%$ \\
\hline Tem controle emocional & - & $10 \%$ & $20 \%$ & $70 \%$ \\
\hline Adapta-se bem às mudanças e novas situações & - & - & $70 \%$ & $30 \%$ \\
\hline Gerencia conflitos no ambiente de trabalho & - & - & $20 \%$ & $80 \%$ \\
\hline
\end{tabular}

Fonte: elaborado pelas autoras com base nos dados da pesquisa

\subsection{Análise das competências de negócios}

As competências de negócios são atribuídas pela interação do campo organizacional e as ações dos indivíduos responsáveis pelos controles gerenciais internos com os demais stakeholders. A relação determina o interesse e a troca de informações do ambiente externo e interno, em prol de estabelecer a gestão e comunicação social, ou seja, segundo Fleury e Fleury (2004), as Competências de Negócios são relacionadas à interação da empresa com as oportunidades, ameaças, pontos fortes e fracos do negócio orientados para as necessidades e exigências do mercado, clientes e concorrentes.

Foram apresentadas dezessete competências de negócios aos participantes da pesquisa com o objetivo de identificar a frequência do uso de cada uma delas, na mesma escala Likert já apresentada anteriormente, identificadas a partir do levantamento bibliográfico realizado para a pesquisa.

$\mathrm{Na}$ análise das competências de negócios, todos os respondentes afirmaram que usam muito apenas duas delas que são: pensar e agir estrategicamente e ter foco na qualidade em todas as decisões tomadas. Isto, mais uma vez, vem contribuir com as ideias de que os responsáveis pelas atividades de controladoria estão ocupando funções gerenciais nas empresas, concordando com diversos autores, já citados anteriormente, como Schmidt e Santos (2014) e Lunkes e Schnorrenberger (2009). 
Foram identificadas apenas três competências como não sendo utilizadas por um pequeno percentual dos respondentes: tem orientação para o Cliente/Fornecedor, realiza a gestão de contratos e busca inovação organizacional (Pesquisa \& Desenvolvimento). Isto confirma uma atuação com foco mais interno na gestão organizacional desses profissionais, que atuam nas atividades de controladoria dessas empresas pesquisadas, porque elas faziam parte do grupo das menores empresas, dentre as pesquisadas.

Dez competências de negócios listadas foram identificadas como de pouco uso por parte dos respondentes com até 30\% deles: promove ações de interação da empresa com seu ambiente; tem capacidade de tomar decisão com imparcialidade; tem orientação para o Cliente/Fornecedor; interage com os prestadores de serviços/terceirizações; relaciona-se com outras empresas parceiras e associações; realiza o acompanhamento técnico dos projetos. Isto se justifica para o grupo de empresas de pequeno porte, que também correspondeu a 30\% dos participantes, pois tendo uma atuação muito restrita, estes não possuem terceirizados, geralmente, não elaboram projetos técnicos e têm uma atuação bem local.

Pela primeira vez na análise de uso das competências apresentadas aos participantes da pesquisa, a ênfase esteve no geralmente usa, o que não foi identificado dentre as competências técnicas e sociais. Isto talvez tenha ocorrido, porque sendo a maioria das empresas de médio porte, não possui uma unidade de controladoria, e as atividades são desempenhadas por um gestor ou pelo próprio sócio e, assim, sua amplitude de ação seja mais restrita.

É interessante constatar que as competências de negócios mais usadas se relacionam com a gestão, tomada de decisão, processos e busca por resultados. Estudos citados anteriormente, em destaque o de Machado et al. (2010, p. 32) que identificou as competências dos controllers nas cem maiores empresas de Santa Catarina, defendem que "a controladoria está se tornando parte da alta administração, participando da formulação e da implementação de estratégias, cabendo-lhe a tarefa de traduzir o plano estratégico em medidas operacionais e administrativas", foram parcialmente confirmados neste estudo, apesar de ter sido realizado com pequenas e médias empresas e no Estado de Pernambuco.

Apenas $10 \%$ das empresas que participaram da pesquisa usam muito questões voltadas para responsabilidade socioambiental e acompanhamento técnico dos projetos. Salientando que corresponderam às empresas com maior número de empregados e de médio porte. O quadro 6 sintetiza a frequência de uso das competências de negócios. 
Quadro 6 - Percentual de Utilização das Competências de Negócios

\begin{tabular}{|c|c|c|c|c|}
\hline \multirow{2}{*}{$\begin{array}{c}\text { Competências de Negócios } \\
\text { (relacionadas aos objetivos organizacionais) }\end{array}$} & \multicolumn{4}{|c|}{ Frequência de uso } \\
\hline & Não usa & $\begin{array}{l}\text { Usa } \\
\text { pouco }\end{array}$ & $\begin{array}{c}\text { Geralmente } \\
\text { usa }\end{array}$ & $\begin{array}{l}\text { Usa } \\
\text { muito }\end{array}$ \\
\hline $\begin{array}{l}\text { Promove ações de interação da empresa com seu } \\
\text { ambiente }\end{array}$ & - & $30 \%$ & $40 \%$ & $30 \%$ \\
\hline $\begin{array}{l}\text { Tem capacidade de tomar decisão com } \\
\text { imparcialidade }\end{array}$ & - & $10 \%$ & $50 \%$ & $40 \%$ \\
\hline Pensa e age estrategicamente & - & - & - & $100 \%$ \\
\hline $\begin{array}{l}\text { Sabe organizar o tempo para realizar diversas } \\
\text { atividades }\end{array}$ & - & - & $40 \%$ & $60 \%$ \\
\hline $\begin{array}{l}\text { Tem foco na qualidade em todas as decisões que } \\
\text { toma }\end{array}$ & - & - & - & $100 \%$ \\
\hline $\begin{array}{l}\text { Busca melhoria contínua dos processos em que } \\
\text { participa }\end{array}$ & - & - & $40 \%$ & $60 \%$ \\
\hline Tem orientação para Resultados & - & - & $40 \%$ & $60 \%$ \\
\hline Tem orientação para o Cliente/Fornecedor & $10 \%$ & $10 \%$ & $60 \%$ & $20 \%$ \\
\hline $\begin{array}{l}\text { Interage com os prestadores de } \\
\text { serviços/terceirizações }\end{array}$ & - & $20 \%$ & $60 \%$ & $20 \%$ \\
\hline É criativo para solucionar problemas empresariais & - & - & $60 \%$ & $40 \%$ \\
\hline $\begin{array}{l}\text { Relaciona-se com outras empresas parceiras e } \\
\text { associações }\end{array}$ & - & $20 \%$ & $30 \%$ & $50 \%$ \\
\hline Realiza o acompanhamento técnico dos projetos & - & $20 \%$ & $70 \%$ & $10 \%$ \\
\hline Faz a análise de risco organizacional & - & $10 \%$ & $70 \%$ & $20 \%$ \\
\hline Realiza a gestão de contratos & $10 \%$ & $30 \%$ & $40 \%$ & $20 \%$ \\
\hline Age com responsabilidade socioambiental & - & $30 \%$ & $60 \%$ & $10 \%$ \\
\hline $\begin{array}{l}\text { Tem preocupação com segurança e saúde na } \\
\text { empresa }\end{array}$ & - & $10 \%$ & $40 \%$ & $50 \%$ \\
\hline $\begin{array}{l}\text { Busca inovação organizacional (Pesquisa \& } \\
\text { Desenvolvimento) }\end{array}$ & $10 \%$ & - & $50 \%$ & $40 \%$ \\
\hline
\end{tabular}

Fonte: elaborado pelas autoras com base nos dados da pesquisa

\section{Conclusões do estudo}

O presente estudo teve por objetivo analisar as competências individuais utilizadas pelos profissionais de controladoria em empresas comerciais da Região Metropolitana do Recife, Pernambuco, e sua frequência de utilização. O controller, que não obrigatoriamente recebe esta denominação, é responsável por diversas atribuições técnicas e gerenciais, bem como em nível operacional e estratégico.

Buscou-se identificar as competências individuais e classificá-las quanto ao seu uso, seguindo a classificação de Fleury e Fleury (2004), que as divide em competências técnicas, de negócios e sociais. As competências técnicas: fornece suporte informacional à gestão empresarial e elabora relatórios gerenciais, sendo estas as que foram identificadas por todos os respondentes como competências que usam muito, acompanhadas pelas competências: assessora a cúpula administrativa e conhecimentos na área financeira e supervisiona a contabilidade.

Nota-se que o conhecimento na área contábil, financeira e tributária é muito utilizado pelos respondentes, o que confirma o que os autores estudados definem como principias áreas de atuação dos controladores, contudo o mesmo não aconteceu 
com os conhecimentos na área de Tecnologia da Informação (TI) e de Recursos Humanos.

As competências sociais também foram levantadas e a mais usada se refere à persistência e não desistir frente aos obstáculos, seguida por ter integridade e confiança. Percebeu-se que entre as competências sociais, as respostas não foram tão uniformes quanto em relação às competências técnicas. Já na análise das competências de negócios, todos os respondentes afirmaram que usam muito apenas duas delas que são: pensar e agir estrategicamente e ter foco na qualidade em todas as decisões tomadas.

Embora não se possa deixar de salientar a limitação do presente estudo, que trabalhou com um número reduzido de empresas comerciais em Pernambuco, os dados levantados e as informações analisadas mostram que os estudos realizados no levantamento bibliográfico foram, em grande parte, confirmados para a amostra trabalhada. Assim, este estudo contribui com o entendimento sobre a utilização das competências individuais dos profissionais da controladoria e pode servir de subsídio para novos estudos em outras realidades.

\section{Referências}

AMORIM, T. N. G. F. ; SILVA, L. de B. . GESTÃO POR COMPETENCIA: NUANCES E PECULIARIDADES. Revista dos Programas de Mestrado do Centro Universitário UNA, v. 16, p. 103-119, 2011.

ANTHONY. R. N.; GOVINDARAJAN, V. Sistemas de controle gerencial. São Paulo: Atlas, 2001. ATKINSON, Anthony A. et al. Contabilidade gerencial. São Paulo: Atlas, 2000.

BA, S. A. C. ; CASTRO, P. A. ; SOUZA, J. C. .Tipologia e importância das competências individuais demandadas aos gestores durante a realização de suas atividades: estudo de caso em uma montadora. Indagatio Didactica, v. 5, p. 627, 2013.

BEUREN, I.M.; CZESNAT, A. F. de O.; SILVA, M.; Papel da controladoria na adequação às contingências ambientais das agroindústrias de carne e derivados listadas na BOVESPA. OrganizaçõesRurais\&Agroindustriais, Lavras, v. 15, n. 3, p. 381-396, 2013.

BOYATZIS, R. The competent manager: a model for effective performance. New York: Wiley, 1982.

BORGES, T. N.; GIL, A. L.; PARISI, C. O controller como gestor da tecnologia da informação: realidade ou ficção? Revista de Administração Contemporânea, Rio de Janeiro, v. 9, n. 4, p. 119-140, out./nov./dez. 2005.

BORINELLI, M. L. Estrutura conceitual básica de Controladoria: sistematização à luz da teoria e da práxis. Tese de Doutorado, Programa de Pós-graduação em Ciências Contábeis, Universidade de Sao Paulo, Sao Paulo, SP, Brasil, 2006. 
BORINI, F. M.; FLORIANI, D. E.; FLEURY, M. T. L. Relação entre tamanho e desenvolvimento de competências organizacionais em multinacionais brasileiras. Revista de Administração, v. 47, n. 4, p. 596-608, 2012.

CALIJURI, M. S. S., SANTOS, N. M. B. F.; SANTOS, R. F. Perfil do controller no contexto organizacional atual brasileiro. 9ํㅡㄴ Congresso Internacional de Custos. Florianópolis-Brasil: ABC, 2005.

CARDOSO, R. L.; MENDONÇA NETO, O. R.; OYADOMARI, J. C. Os estudos internacionais de competências e os conhecimentos, habilidades e atitudes do contador gerencial brasileiro: análises e reflexões. BBR - Brazilian Business Review, v. 7, n. 5, p. 91-113, 2010.

CARVALHO, I.; PASSOS, A.; SARAIVA, S. Recrutamento e seleção por competências. Rio de Janeiro: Editora FGV, 2008.

CATELLI. A. Controladoria: Uma abordagem da Gestão Econômica GECON. São Paulo: Atlas, $2^{\mathrm{a}}$ ed, 2001.

CAVALCANTE, D..S; LUCA, Márcia M. M. de; PONTE, Vera M. R.; GALLON,Alessandra V. Características da controladoria nas maiores companhias listadas naBM\&FBovespa. Revista Universo Contábil, v. 8, n. 3, p. 113-134, 2012.

CHAGAS, M. B.; BONZANINI, O. A. Controladoria é staff ou linha?Revista de Administração. Ano II, n‥ 3, segundo semestre de 2003.

COLTON, S. D. The Changing Role of The Controller. Journal of Cost Management., n.6, p. 5-6, 2001.

CRESWELL, J. W. Projeto de Pesquisa: métodos qualitativo, quantitativo e misto, 3. ed. Porto Alegre: Artmed, 2010.

CRISPIM, G., CABRAL, L. M. M. do A. C. elIBONATI, J. J. Aspectos comportamentais: A controladoria como fator de influência no comportamento humano. Advances in Scientific and Applied Accounting, v.4, n.3, p. 379-405, 2011.

CUGANESAN, S.; DUNFORD, R.; PALMER, I. Strategic management accounting and strategy practices within a public sector agency.Management AccountingResearch, PublishedbyElsevierLtda, 2012.

CUNHA JÚNIOR, A. M. Mortalidade e sobrevivência da micro e pequena empresa no Estado da Paraíba (2001-2005): uma abordagem institucional. Dissertação de Mestrado. Universidade Federal da Paraíba. João Pessoa, 2009.

DIAS, B. B. O papel da controladoria no suporte ao processo de geração de informações voltadas ao controle de gestão operacional em empresa prestadora de serviços de hemodinâmica. DissertaçãodeMestrado em Engenharia da Produção, 2002. 
DIEHL, C. A.; RODNISKI, C. M. O Papel da Controladoria em Relação ao Grau de Centralização das Organizações. Sociedade, Contabilidade e Gestão, Rio de Janeiro, v. 7, n. 1, jan/jun 2012.

DUTRA, J. S.;FLEURY, M. T. L.; RUAS, R. Competências - Conceitos Métodos e Experiências. São Paulo: Atlas, 2008.

FAGUNDES, P.M.; SEMINOTTI, N. A Dimensão Coletiva da Liderança. Caderno IHUldéias, Ano 7, no 120, São Leopoldo: Instituto HumanitasUnisinos, 2009.

FARIA, J. H. de. Análise Crítica das Teorias e Práticas Organizacionais. São Paulo: Atlas, 2007.

FERNANDES, A. M.; GALVÃO, P. R. A Controladoria como ferramenta de gestão nas micro e pequenas empresas: um estudo da viabilidade e da relação custo benefício. Revista de Tecnologia Aplicada, v. 5, n. 1, p. 3-16, 2016.

FERNANDES, C. Um estudo exploratório das funções da controladoria em pequenas e médias empresas: Dissertação de Mestrado: UNIMEP. 2007

FIGUEIREDO, S.; CAGGIANO, P. C. Controladoria: teoria e prática, 3.ed., São Paulo: Atlas, 2004.

FLEURY, A.; FLEURY, M. T.; Estratégias empresariais e formação de competências: um quebra-cabeça caleidoscópio da indústria brasileira. São Paulo: Atlas, 2000.

. Alinhando estratégia e competências. Revista de Administração de Empresas, v. 44, no1, p. 44-57, 2004.

GARRISON, Ray H.; NOREEN, Eric; W. BREWER, Peter C. Contabilidade Gerencial. 9. ed., LTC: Rio de Janeiro, 2001.

HORNGREN, C.T., SUNDEM, G. L., STRATTON, W. O. Contabilidade gerencial. 12a․ ed. São Paulo: Pearson, 2004.

IBGE PNAD. Pesquisa Nacional por Amostra de Domicílios (PNAD) 2014. Disponível em:http://www.ibge.gov.br/home/estatistica/populacao/trabalhorendimento/pnad2014 Acesso em: 18 de março de 2017.

KÜPPER, P. Controlling: Konzeption, Aufgaben und Instrumente, 4. Auflage. Berlin: MSG, 2005.

LE BOTERF, G. Desenvolvendo a competência dos profissionais. Porto Alegre: Artmed, 2003.

LUNKES, R. J.; SCHNORRENBERGER, Darci; Controladoria: na coordenação dos sistemas de gestão. São Paulo: Atlas, 2009. 
LUNKES, R. J.; SCHNORRENBERGER, Darci; ROSA, Fabricia Silva da. ControllershipFunctions: ananalysis in theBrazilianscenario. Revista Brasileira de Gestão e Negócios, São Paulo, v. 15, n. 47, p. 283-299, abr./jun. 2013.

LUNKES, R. J.; MACHADO, A. O.; ROSA, F. S. da; TELLES, J. Funções da controladoria: Um estudo nas 100maiores empresas do Estado de Santa Catarina. Análise Psicológica [online]. vol. 29, n.2, p. 345-361, 2011.

MAXIMIANO, A. C. A. Introdução à Administração. 6. ed. São Paulo: Atlas, 2006.

McCLELLAND, D. C. Testing for competence rather than intelligence. American Psychologist, p. 1-14, jan. 1973.

MINAYO, M.C. de S. Pesquisa social: teoria, método e criatividade. 22 ed. Rio de Janeiro: Vozes, 2003.

MONTEIRO, J. M.; BARBOSA, J. D. Controladoria empresarial: gestão econômica para as micro e pequenas empresas. Revista da Micro e Pequena Empresa, v. 5, n. 2, p. 38-59, 2011.

MORANTE, A. S.; JORGE, F.T. Controladoria: análise financeira, planejamento e controle orçamentário. São Paulo: Atlas, 2008.

OLIVEIRA, D.de P. R. Planejamento Estratégico: Conceitos, Metodologia e Prática. São Paulo: Atlas, 2005.

PAULO, W. L. de; FERNANDES, F. C.;RODRIGUES, L. G. B.; EIDT, J. Riscos e controles internos: uma metodologia de mensuração dos níveis de controle de riscos empresariais. Revista Contabilidade Financeira, USP, São Paulo, n. 43,p. 49-60, 2007.

PADOVEZE, C.L. Controladoria estratégica e operacional. 3. ed. São Paulo: Atlas,2005.

PARRY, S. B. The quest for competencies. Training, p. 48-54, July 1996.

PRAHALAD, C. K.; HAMEL, G.The core competence of the corporation. Harvard Business Review, v. 68, n. 3, p. 79-91, May/June 1990.

QUEIROZ, L. M. N. de. Investigação do uso da informação contábil na gestão das micro e pequenas empresas da região do Seridó Potiguar. Dissertação de Mestrado. Natal, 2005.

RAUPP, F. M.; BEUREN, I. M. Metodologia da pesquisa aplicada às ciências sociais. IN: BEUREN, Ilse Maria. Como elaborar trabalhos monográficos em contabilidade. 3ed. São Paulo: Atlas, 2006.

REIS, G. G.; FLEURY, M. T. L.; FLEURY, A. C. C.; ZAMBALDI, F. Competências das Multinacionais Brasileiras: impactos de um "Cabo de Guerra" entre Legados Culturais e Mentalidade Global. Brazilian Business Review, v. 12, n. 1, p. 57-82, 2015. 
RESENDE, E. O Livro das Competências: Desenvolvimento das Competências, Organizações e Sociedade. Qualitymark. Rio de Janeiro. 2003.

RODRIGUES, M. S.; AMARAL, M. S. do. O ensino da disciplina de controladoria nos programas de pós-graduação em nível de especialização em ciências contábeis e o profissional controller atuante no mercado de trabalho. Enfoque: Reflexão Contábil, v. 25, n. 3, p. $17-28,2008$.

SANDBERG, J. Understanding human competence at work: an interpretative approach.Academy of Management Journal, v. 43, n. 1, p. 9-25, 2000.

SANDBERG, J; DALL'ALBA, G. Reframing competence development at work. In: Castleton, G., Gerber, R.; Pillay, H. (Orgs.) Improving Workplace Learning. NovaPublishers: New York, 2006.

SPENCER, L. M.; SPENCER, S. M. Competence at work: models for superior performance. New York: John Wiley \& Sons, 1993.

SCHMIDT, P.; SANTOS, J. L. dos. A Controladoria e a análise discriminante do consumidor do e-commerce. Revista Internacional de Economia y Gestion de las Organizaciones, v. 3, p. 1-15, 2014.

ZARIFIAN, P. Objetivo competência: por uma nova lógica. São Paulo: Atlas, 2001.

WAHLMANN, G. C. Um Estudo Exploratório Sobre a Atividade de Controladoria nas Microempresas na Cidade de Ubatuba. São Paulo. Fundação Escola de Comércio Álvares Penteado - Fecap, 2003. 